\title{
High ceruloplasmin levels are associated with obsessive compulsive disorder: a case control study
}

\author{
Osman Virit ${ }^{1}$, Salih Selek*2, Mahmut Bulut ${ }^{1}$, Haluk Asuman Savas ${ }^{1}$, \\ Hakim Celik ${ }^{3}$, Ozcan Erel $^{3}$ and Hasan Herken ${ }^{4}$
}

\begin{abstract}
Address: ${ }^{1}$ Department of Psychiatry, Medical Faculty, Gaziantep University, Gaziantep, Turkey, ${ }^{2}$ Department of Psychiatry, Kahramanmaras State Hospital, Kahramanmaras, Turkey, ${ }^{3}$ Department of Clinical Biochemistry, Medical Faculty, Harran University, Sanliurfa, Turkey and ${ }^{4}$ Department of Psychiatry, Medical Faculty, Pamukkale University, Denizli, Turkey

Email: Osman Virit - drosmanvirit@yahoo.com.tr; Salih Selek* - drselek@hotmail.com; Mahmut Bulut - drmahmutbulut@yahoo.com; Haluk Asuman Savas - drhaluksavas@yahoo.com; Hakim Celik - hakimcell@yahoo.com; Ozcan Erel - erelozcan@yahoo.com;

Hasan Herken - hasanherken@yahoo.com

* Corresponding author
\end{abstract}

Published: 18 November 2008

Behavioral and Brain Functions 2008, 4:52 doi:10.1 I86/1744-908I-4-52
Received: I June 2008

Accepted: 18 November 2008

This article is available from: http://www.behavioralandbrainfunctions.com/content/4/1/52

(C) 2008 Virit et al; licensee BioMed Central Ltd.

This is an Open Access article distributed under the terms of the Creative Commons Attribution License (http://creativecommons.org/licenses/by/2.0), which permits unrestricted use, distribution, and reproduction in any medium, provided the original work is properly cited.

\begin{abstract}
Background: Alterations in ceruloplasmin are currently assumed as one of the mechanisms underlying the development of a number of neurodegenerative disorders. Several studies indicate that elevated serum ceruloplasmin levels may play a role in schizophrenia by exacerbating or perpetuating dopaminergic dysregulation. No study investigating the relationship between ceruloplasmin and obsessive-compulsive disorder (OCD) has been published to date. Nowadays $O C D$ is increasingly speculated to be a different disorder than other anxiety disorders, and rather is considered to be more similar to psychotic disorders. The objective of this study to explore whether there is an association of ceruloplasmin with $O C D$ as in schizophrenia.
\end{abstract}

Method: 26 pure OCD and 9 co-morbid OCD patients from Gaziantep University Sahinbey Research Hospital, Psychiatry Clinics, diagnosed according to the DSM IV and 40 healthy controls were included in the study. Blood samples were collected; ceruloplasmin levels were measured.

Results: The mean ceruloplasmin level in pure OCD patients, co-morbid OCD patients, and control group persons were $544.46 \pm 26.53,424.43 \pm 31.50$ and $222.35 \pm 8.88 \mathrm{U} / \mathrm{L}$ respectively. Results of all 3 groups differ significantly. Positive predictive value of ceruloplasmin for that cut-off point is $31 / 3 \mathrm{I}$ (100\%) and negative predictive value is $40 / 44$ (9I\%) in our group.

Conclusion: Although the nature of relationship is not clear there was an association between ceruloplasmin levels and OCD in our study.

\section{Background}

Ceruloplasmin is a protein of the $\alpha 2$-globulin fraction of human blood serum. It contains $95 \%$ of serum copper. Hepatocytes synthesize ceruloplasmin, which is subsequently found in plasma, but extrahepatic gene expres- sion has been documented for this protein. Among the organs expressing ceruloplasmin gene are the brain, lung, spleen, and testis. In the central nervous system of humans and other mammals, ceruloplasmin is expressed in neurons and astroglial cells, e.g., of the cerebral micro- 
vascular network. Ceruloplasmin carries copper from liver to numerous tissues. The symptoms of Wilson's disease, that is characterized by low levels of ceruloplasmin with subsequent copper deposition in various tissues including brain, often mimic those of schizophrenia. Ceruloplasmin is also an iron oxidase; for this capacity, it has been labeled ferroxidase I. In addition, ceruloplasmin is an acute phase reactant, whose concentration increases in inflammation, infection, trauma, etc. For these properties it is known as an antioxidant. Ceruloplasmin has other functions, including the oxidation of serotonin, epinephrine, and norepinephrine. The relation of ceruloplasmin to neurodegenerative processes in human was documented. Alterations in ceruloplasmin levels are currently regarded as one of the mechanisms underlying the development of a number of neurodegenerative disorders. Vassiliev et al. (2005) discussed largely ceruloplasmin in neurodegenerative diseases [1].

There are numerous studies reporting an association between ceruloplasmin and schizophrenia, but the nature of the relationship remains unclear [2-9]. One possible explanation has been ceruloplasmin and copper relation since abnormalities in copper levels or metabolism may lead to dopaminergic dysregulation. In addition, ceruloplasmin has been associated with some clinical features of schizophrenia $[2,4,5,8]$. Some symptomatology of OCD resembles to schizophrenia. Also dopaminergic dysregulation in the certain areas of brain may play a role in OCD etiopathogenesis as in schizophrenia $[10,11]$. Nowadays, OCD is increasingly speculated to be a different disorder than other anxiety disorders. OCD is rather thought to be similar to psychotic disorders $[12,13]$. The objective of this study is to explore, whether there is a role of ceruloplasmin in OCD as in schizophrenia. Therefore, we investigated the possible association between serum ceruloplasmin levels and OCD. We have not identified any study on this issue in the literature prior to our study.

\section{Methods \\ Patients}

37 consecutive OCD patients, who were diagnosed based on DSM-IV (30 females, 7 males), and followed by Department of Psychiatry, Gaziantep University Hospital after they applied to Anxiety Disorders Unit, were enrolled after they provided informed consent. The diagnoses of OCD were established by one psychiatrist (SS). Nine of the 37 patients had psychiatric comorbidities. In addition to OCD, five of 9 suffered from other anxiety disorders, 2 from depression, 1 from schizoaffective disorder. The remaining one patient had more than two psychiatric disorders. Patients with comorbid diagnoses were included in the study if the other psychiatric conditions were in remission. Remission was defined as a score below or equal to two ("borderline mentally ill") on Clinical Glo- bal Impression (CGI)-Severity Scale [14]. All patients were on their OCD treatment provided naturalistically by the same psychiatrist. The data were collected within two months. Exclusion criteria were as follows: alcohol or substance dependence according to the DSM-IV, tardive dyskinesia related to neuroleptics, presence of severe organic condition, use of any antioxidant agent (i.e. vitamins $\mathrm{E}$ and C), presence of epilepsy or other severe neurological disorder which were previously found to be associated with oxidative status, presence of infectious disease, excessive obesity and insufficient sampling. Two patients were excluded due to insufficient sampling.

\section{Controls}

The control group consisted of forty healthy volunteers who were recruited from university staff ( 30 females, 10 males). They were free of any medication for at least 6 weeks prior to blood sampling. None of the control subjects were alcohol consumer, heavy smoker, or had ever taken any psychotropic drugs. They had no history or family history of any psychiatric disorder. The controls were matched with the patients in regards to sex and age. All subjects signed written informed consent, which had been approved by the local ethics committee in accordance with the Declaration of Helsinki. Physical and neurological examinations were performed on each of the patients and controls. Only subjects with normal physical and neurological exams and without any exclusion criteria were admitted to the study.

\section{Instruments}

Sociodemographic information form

All subjects were evaluated by a semi-structured questionnaire, which was developed in accordance with clinical criteria and available information sources. Gender, age, marital status, smoking habits, socioeconomic status, and duration of illness were recorded before venous blood sampling.

\section{Yale-Brown Obsession Compulsion Scale}

Yale-Brown Obsession Compulsion Scale in Turkish (YBOCS) is a scale that assesses the severity of OCD without focusing on the contents of obsession and compulsion [15]. It has ten items. Each item is assessed between 0 and 4 points by a clinician. Patients were rated by the same psychiatrist (SS) twice, on the venous sampling day for initial Y-BOCS evaluation and after two months for late YBOCS scores. During second evaluation the rater was blinded to the serum measures.

\section{Blood sampling}

Venous blood samples from left forearm vein were collected into $5 \mathrm{ml}$ vacutainer tubes between 7 and 8 a.m. after overnight fasting. The blood samples were centrifuged at $2000 \mathrm{rpm}$ for $10 \mathrm{~min}$ to obtain sera. Samples 
were stored frozen at $-40^{\circ} \mathrm{C}$ before analysis. The biochemical analyses were made after all the blood samples were collected.

\section{Ceruloplasmin measurement}

Erel's ceruloplasmin measurement method is used. This method is automated, colorimetric, and based on the enzymatic oxidation of ferrous ion to ferric ion [16]. The results were expressed in milligrams per deciliter, and the precision of this assay is within 3\%. For a details see Erel $[16,17]$.

\section{Apparatus}

A Cecil 3000 spectrophotometer with a temperature controlled cuvette holder (Cecil) and an Aeroset automated analyzer (Abbott) were used [16].

\section{Statistical Analysis}

The obtained data were evaluated by SPSS for Windows 13.0. The comparisons were performed by ANOVA with Tukey HSD (for two-group and all-group comparisons). For correlation evaluations, the Spearman correlation (two-tailed) was used. The comparison of sociodemographic characteristics was performed by the independent samples T test. Two-tailed forms were used. The comparison of serum levels among groups was performed by Post Hoc Tukey's Test and Dunnett's Test. The statistical significance was accepted as $\mathrm{p}<0.05$. Using receiver operating characteristic (ROC) analysis, curve was plotted of sensitivity versus 1 minus specificity for all possible cut-off scores of serum ceruloplasmin level as a diagnostic test. The accuracy of the serum ceruloplasmin level as a diagnostic test in OCD is represented by, and is directly proportional to, the area under the curve (AUC).

\section{Results}

The demographic and clinical data of the subjects were summarized in Table 1. The mean ceruloplasmin levels in pure OCD patients, co-morbid OCD patients and control group persons were $544.46 \pm 26.53,424.43 \pm 31.50$ and $222.35 \pm 8.88 \mathrm{U} / \mathrm{L}$ respectively. The mean ceruloplasmin levels were significantly higher in pure and co-morbid OCD groups than that of control group $(\mathrm{p}<0.01)$. In pure OCD group mean ceruloplasmin level was significantly higher than co-morbid OCD group $(\mathrm{p}<0.01)$. In plotted ROC curve (Figure 1) OCD could be predicted for ceruloplasmin over $342.85 \mathrm{U} / \mathrm{L}$ level with $88.6 \%$ sensitivity and $100 \%$ specificity (Table 2 ). Positive predictive value of ceruloplasmin for that cut-off point was $31 / 31$ (100\%) and negative predictive value was $40 / 44$ (91\%) in our study. There was no correlation between ceruloplasmin and illness duration or YBOCS scores ( $p>0.05)$.

\section{Discussion}

The association between ceruloplasmin and OCD has not been investigated so far. To the best of our knowledge this is the first report about elevated ceruloplasmin levels in OCD patients. Ceruloplasmin abnormalities have been implicated in schizophrenia, even the nature of relationship remains unclear. Since abnormalities in copper metabolism may lead to dopaminergic dysregulation, the ceruloplasmin and copper relationship might be important in schizophrenia [9]. Ceruloplasmin largely determines copper concentration, and plays a critical role in the interpretation of copper results $[18,19]$. One suggested strategy to study copper is to measure ceruloplasmin levels, because approximately 95\% of the copper in blood is bound to ceruloplasmin, therefore increases in ceruloplasmin would be expected to correlate directly with increases in serum copper. Both increased serum copper and ceruloplasmin levels have been found in the same schizophrenic patients [9]. The importance of dopamine has been largely studied in schizophrenia and copper plays role in the synthesis and metabolism pathways of dopamine. For example, the copper-dependent enzyme tyrosinase shunts tyrosine away from DOPA production, copper inhibits dopa-decarboxylase thereby inhibiting dopamine production, the copper-dependent enzyme dopamine beta-hydroxylase catalyzes the breakdown of dopamine into norepinephrine, and the copperdependent enzyme monoamine oxidase (MAO) catalyzes the breakdown of dopamine into other metabolites. Elevated copper and corresponding changes in dopamine may result in increased number or sensitivity of post-synaptic dopamine receptors in certain areas of the brain. Thus, elevated ceruloplasmin results in increased copper, which may lead to psychotic symptoms through the mentioned mechanism. Similarly, psychotic symptoms occur in Wilson's disease, in which there is copper deposition in liver, cornea, and brain due to lack of ceruloplasmin. This leads to over exposure of brain to copper $[9,20]$.

As in schizophrenia, association between ceruloplasmin and OCD might be examined through ceruloplasmin and copper relationship, since there is now growing evidence that the dopamine system may be involved also in the pathophysiology of OCD [21-23]. An association between OCD and increased midbrain dopamine neurotransmission has been reported. In addition, atypical antipsychotics, such as risperidone and quetiapine, may augment the response to selective serotonin reuptake inhibitors (SSRIs) in patients with refractory OCD. This would seem to point to an increase in dopaminergic system activity in OCD [24,25]. As in schizophrenia increased ceruloplasmin levels may increase copper levels, which may lead to dopaminergic dysregulation in OCD. 


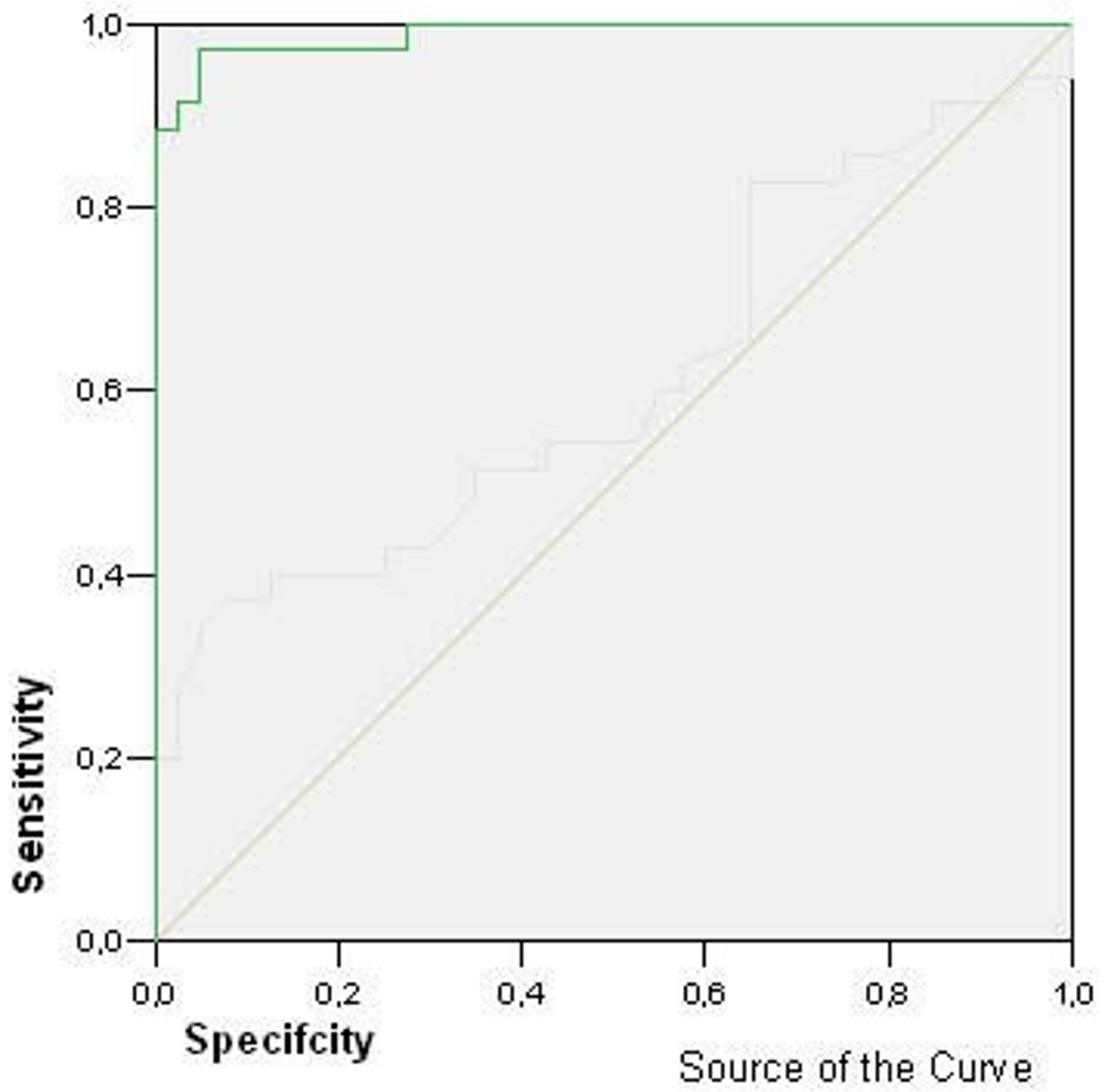

Diagonal segments are produced by ties.

Ceruloplamin Reference Line

Figure I

In plotted ROC curve, disease condition (OCD) can be predicted via ceruloplasmin levels over 342.85 U/L with $\mathbf{8 8 . 6} \%$ sensitivity and $100 \%$ specificity. 
Table I: Sociodemographic and clinical characteristics of patients

\begin{tabular}{lll}
\hline & All Patients & Pure OCD \\
\hline Sex: female/male (n) & $28 / 7$ & $22 / 4$ \\
Age: Mean \pm SD & $33.4 \pm 11.2$ & $34.5 \pm 11.0$ \\
Illness duration (years): Median & $5(I-30)$ & $5(1-30)$ \\
YBOCS-initial: Mean \pm SD & $9.8 \pm 5.7$ & $9.7 \pm 5.8$ \\
YBOCS-later: Mean \pm SD & $9.2 \pm 5.9$ & $8.5 \pm 6.0$
\end{tabular}

However, association between ceruloplasmin and OCD may be explained via copper and serotonin relationship, too. Copper induces oxidation of serotonin and the products of 5-HT oxidation are or have the potential to be neurotoxic, especially on serotonergic receptors. Copper structurally alters serotonin by effectively converting functional 5-HT into dimeric species. It has been suggested that this process might play a role in copper related neurodegenerative diseases [26].

An intriguing link between copper and 5-HT is suggested by symptoms observed in a number of diseases, for instance, in patients with Wilson's disease depression, anxiety, personality changes, and cognitive impairment are among the common symptoms, and a number of studies indicate that disruption of the serotonergic system may partly explain these changes $[27,28]$. It is well known that serotonin has been implicated in the neurobiology OCD. It has been suggested that OCD might be related to the functioning of brain serotonin systems. This hypothesis is based largely on the notion that SSRIs possess antiobsessional efficacy [29-31]. Neuroimaging studies have been very influential in shaping neurobiological models of OCD. Converging data have implicated a network of brain regions, including the orbitofrontal cortex, striatum, and thalamus, in the pathophysiology of OCD. Most regions of the putatively involved network in OCD are densely innervated by serotonergic or dopaminergic neurons [32]. Also, in animal models and preclinical studies significant interactions between serotonergic and dopaminergic systems in OCD have been reported [33,34].

On the other hand, some in vitro studies have demonstrated that ceruloplasmin is a potent antioxidant, even more potent than albumin and superoxide dismutase [35]. Previous studies suggested an oxidative imbalance in OCD. Selek et al. (2008) reported that total antioxidant status might be increased reactively in OCD [36].

Interestingly, in our study pure OCD patients had a higher mean level of ceruloplasmin than comorbid OCD patients, thus pointing out a more relevant situation between OCD and other disorders. In some schizophrenia studies, plasma ceruloplasmin was associated with subtypes, duration, severity, and antipsychotic treatment of schizophrenia. [3-5,8]. We did not find any association between ceruloplasmin and duration of illness or YBOCS-scores of OCD.

Another finding is with a cut-off point of $342.85 \mathrm{U} / \mathrm{L}$ ceruloplasmin levels OCD can be predicted in our group. The positive predictive value was $100 \%$ and negative predictive value was $91 \%$.

Some limitations of this study include: Sample size is relatively small, not all of the patients have pure OCD, some of them have co-morbid psychiatric disorders, and all patients were receiving drug therapy. The ongoing drug treatments were not interrupted due to ethical considerations.

\section{Conclusion}

To the best of our knowledge, this is the first study about plasma ceruloplasmin in OCD. Although we found that plasma ceruloplasmin was higher in OCD than healthy controls, the role of ceruloplasmin in OCD remains

Table 2: Characteristics and coordinates of ROC Curve

\begin{tabular}{|c|c|c|c|c|}
\hline \multirow[t]{2}{*}{ Variable } & \multirow[t]{2}{*}{ Area under Curve } & \multirow[t]{2}{*}{$P$ value } & \multicolumn{2}{|c|}{ 95\% Confidence Interval } \\
\hline & & & Lower Bound & Upper Bound \\
\hline Ceruloplasmin & 0.989 & $<0.001$ & 0.971 & 1.006 \\
\hline \multicolumn{5}{|c|}{ Coordinates of ROC curve } \\
\hline Variable & Positive if greater or equal to & Sensitivity & Specificity & \\
\hline \multirow[t]{5}{*}{ Ceruloplasmin } & 327.8500 & 0.914 & 0.025 & \\
\hline & 332.3500 & 0.886 & 0.025 & \\
\hline & 342.8500 & 0.857 & 0.000 & \\
\hline & 362.2500 & 0.829 & 0.000 & \\
\hline & 376.9500 & 0.792 & 0.000 & \\
\hline
\end{tabular}


unclear. Our results suggest that alterations in ceruloplasmin levels may reflect a response to illness that serves as some kind of non specific protective mechanism or duration effect of the illness or drug therapy. Further research is warranted to replicate our findings and also to study further the relationship between ceruloplasmin and OCD.

\section{Abbreviations}

OCD: Obsessive Compulsive Disorder; Y-BOCS: YaleBrown Obsession Compulsion Scale.

\section{Competing interests}

The authors declare that they have no competing interests.

\section{Authors' contributions}

OV drafted the manuscript and performed the analysis and interpretation of the statistical data together with other authors. SS performed to design the study, longitudinal study with respect to OCD in which the subjects of this study are included and the statistical analyses, and has been involved in drafting the manuscript. MB performed longitudinal study with respect to OCD in which the subjects of this study are included together with SS. HC and OE carried out the biochemical examination, performed the analysis and interpretation of the statistical data together with SS. HH and HS has been involved to design the study and the analysis and interpretation of the statistical data. All authors read, provided comments, and approved the final manuscript.

\section{Acknowledgements}

We thank to participants and the staff of the Gaziantep University Sahinbey Research Hospital.

\section{References}

I. Vassiliev V, Harris ZL, Zatta P: Ceruloplasmin in neurodegenerative diseases. Brain Res Brain Res Rev 2005, 49:633-640.

2. Puzynski S: Investigations on ceruloplasmin in chronic schizophrenia. Pol Med J 1966, 5: I 484-149I.

3. Alias AG, Vijayan N, Nair DS, Sukumaran M: Serum ceruloplasmin in schizophrenia: significant increase in acute cases especially in catatonia. Biol Psychiatry 1972, 4:231-238.

4. Giner J, Morell M, Osorio C: Serum levels of ceruloplasmin as an index of the clinical evolution in schizophrenic patients. Rev Esp Fisiol 1972, 28:39-42.

5. Chugh T, Dhingra R, Gulati R, Bathla J: Copper metabolism in schizophrenia. Indian J Med Res 1973, 6 I: I |47-I I 52.

6. Domino EF, Krause RR, Thiessen MM, Batsakis JG: Blood protein fraction comparisons of normal and schizophrenic patients. Arch Gen Psychiatry 1975, 32:717-72I.

7. Rahman B, Rahman MA, Hassan Z: Variation of copper and ceruloplasmin levels with liver function tests in schizophrenic patients. Biomedicine 1978, 29:238-241.

8. Morera AL, Henry M, García-Hernández A, Fernández-Lopez L: Acute phase proteins as biological markers of negative psychopathology in paranoid schizophrenia. Actas Esp Psiquiatr 2007, 35:249-252.

9. Wolf TL, Kotun J, Meador-Woodruff JH: Plasma copper, iron, ceruloplasmin and ferroxidase activity in schizophrenia. Schizophr Res 2006, 86: |67-|7|.

10. Wee NJ van der, Stevens H, Hardeman JA, MandI RC, Denys DA, van Megen HJ, Kahn RS, Westenberg HM: Enhanced dopamine transporter density in psychotropic-naive patients with obsessive- compulsive disorder shown by $[123 \mid]\{$ beta\}-CIT SPECT. Am J Psychiatry 2004, I6I( I 2):220I-2206.

II. Kim SJ, Kim CH: The genetic studies of obsessive-compulsive disorder and its future directions. Yonsei Med J 2006, 47(4):443-454.

12. Martin V, Huber M, Rief W, Exner C: Comparative cognitive profiles of obsessive-compulsive disorder and schizophrenia. Arch Clin Neuropsychol 2008, 23(5):487-500.

13. Kitis A, Akdede BB, Alptekin K, Akvardar Y, Arkar H, Erol A, Kaya N: Cognitive dysfunctions in patients with obsessive-compulsive disorder compared to the patients with schizophrenia patients: relation to overvalued ideas. Prog Neuropsychopharmacol Biol Psychiatry 2007, 3 I ( I):254-26I.

14. Guy W: Clinical Global Impressions ECDEU Assessment Manual for Psychopharmacology, Revised (DHEW Publ. No. ADM 76-338). National Institute of Mental Health: Rockville, MD; 1976:218-222.

15. Tek C, Ulug B, Rezaki BG, Tanriverdi N, Mercan S, Demir B, et al: Yale-Brown Obsessive Compulsive Scale and US National Institute of Mental Health Global Obsessive Compulsive Scale in Turkish: reliability and validity. Acta Psychiatr Scand 1995, $91(6): 410-413$.

16. Erel O: Automated measurement of serum ferroxidase activity. Clin Chem 1998, 44:23I3-9.

17. Erel O: A novel automated method to measure total antioxidant response against potent free radical reactions. Clin Biochem 2004, 37(2): I I 2-1 I9.

18. Gaffney D, Fell GS, O'Reilly DS: ACP Best Practice No 163: Wilson's disease: acute and presymptomatic laboratory diagnosis and monitoring. J Clin Pathol 2000, 53:807-8I2.

19. Twomey PJ, Viljoen A, House IM, et al.: Relationship between serum copper, ceruloplasmin, and non-ceruloplasmin-bound copper in routine clinical practice. Clin Chem 2005, 5I:1558-1559.

20. Bowman MB, Lewis M: The copper hypothesis of schizophrenia: a review. Neurosci Biobehav Rev 1982, 6:32I-328.

21. Goodman WK, McDougle CJ, Price LH: The role of serotonin and dopamine in the pathophysiology of obsessive-compulsive disorder. Int Clin Psychopharmacol 1992, 7:35-38.

22. McDougle C]: Update on pharmachologic management of OCD: agent and augmentation. J Clin Psychiatry 1997, 58: I I-17.

23. Goodman WK, McDougle C], Price LH, et al.: Beyond the serotonin hypothesis: a role for dopamine in some forms of obsessive compulsive disorder. J Clin Psychiatry 1990, 5 I:36-43.

24. McDougle C], Epperson CN, Pelton GH, Wasylink S, Price LH: A double-blind, placebo-controlled study of risperidone addition in serotonin reuptake inhibitor-refractory obsessivecompulsive disorder. Arch Gen Psychiatry 2000, 57:794-80I.

25. Denys D, van Megen $H$, Westenberg $H$ : Quetiapine addition to serotonin reuptake inhibitor treatment in patients with treatment-refractory obsessive-compulsive disorder: an open-label study. J Clin Psychiatry 2002, 63:700-703.

26. Jones CE, Underwood CK, Coulson EJ, Taylor PJ: Copper induced oxidation of serotonin: analysis of products and toxicity. J Neurochem 2007, 102(4): 1035-1043.

27. Eggers B, Hermann W, Barthel H, Sabri O, Wagner A, Hesse S: The degree of depression in Hamilton rating scale is correlated with the density of presynaptic serotonin transporters in $\mathbf{2 3}$ patients with Wilson's disease. J Neurol 2003, 250:576-580.

28. Hesse S, Barthel H, Hermann W, Murai T, Kluge R, Wagner A, Sabri $O$, Eggers $B$ : Regional serotonin transporter availability and depression are correlated in Wilson's disease. J Neural Transm 2003, II 0:923-933.

29. Barr LC, Goodman WK, Price LH, et al.: The serotonin hypothesis of obsessive compulsive disorder: implications of pharmachologic chalange srudies. J Clin Psychiatry 1992, 53:17-28.

30. Pigott TA: OCD: where the serotonin selectivity begins. J Clin Psychiatry 1996, 57 Suppl 6: I I-20.

31. Blier P, Montigny C: Possible serotonergic mechanisms underlying the antidepressant and ati-obsessive-compulsive disorder responses. Biol Psychiatry 1998, 44:313-323.

32. Insel TR: Toward a neuroanatomy of obsessive-compulsive disorder. Arch Gen Psychiatry 1992, 49:739-744.

33. Swedo SE, Leonard HL, Kruesi MJ, Rettew DC, Listwak SJ, Berrettini W, Stipetic M, Hamburger S, Gold PW, Potter WZ: Cerebrospinal 
fluid neurochemistry in children and adolescents with obsessive-compulsive disorder. Arch Gen Psychiatry 1992, 49:29-36.

34. Brambilla F, Bellodi L, Perna G, Arancio C, Bertani A: Dopamine function in obsessive-compulsive disorder: growth hormone response to apomorphine stimulation. Biol Psychiatry 1997, 42:889-897.

35. Dumoulin MJ, Chahine R, Atanasiu R, Nadeau R, Mateescu MA: Comparative antioxidant and cardioprotective effects of ceruloplasmin, superoxide dismutase and albumin. Arzneimittelforschung 1996, 46:855-86I.

36. Selek S, Herken H, Bulut M, Ceylan MF, Celik H, Savas HA, Erel O: Oxidative imbalance in obsessive compulsive disorder patients: a total evaluation of oxidant-antioxidant status. Prog Neuropsychopharmacol Biol Psychiatry 2008, 32(2):487-49I.

Publish with Bio Med Central and every scientist can read your work free of charge

"BioMed Central will be the most significant development for disseminating the results of biomedical research in our lifetime. "

Sir Paul Nurse, Cancer Research UK

Your research papers will be:

- available free of charge to the entire biomedical community

- peer reviewed and published immediately upon acceptance

- cited in PubMed and archived on PubMed Central

- yours - you keep the copyright

Submit your manuscript here:

http://www.biomedcentral.com/info/publishing_adv.asp 